\title{
Analysis of the Adaptation Capacity of Staphylococcus aureus to Commonly Used Antiseptics by Microplate Laser Nephelometry
}

\author{
C. Wiegand ${ }^{a} \quad$ M. Abel ${ }^{b} \quad$ P. Ruth ${ }^{c}$ U.-C. Hipler \\ ${ }^{a}$ Department of Dermatology, University Medical Center Jena, Jena, ${ }^{\mathrm{b}}$ Lohmann \& Rauscher GmbH and Co. KG, \\ Rengsdorf, and 'Lohmann \& Rauscher GmbH and Co. KG, Neuwied, Germany
}

\section{Key Words}

Antiseptics - Bacterial adaptation - Microplate laser nephelometry · Mupirocin · Staphylococcus aureus

\begin{abstract}
Background: Bacterial colonization and infection are important factors in compromised wound healing. Antiseptics have become an alternative for antimicrobial applications as antibiotic resistance is increasing; they have multiple targets with a broad spectrum of activity. Hence, the risk for developing resistance should be low. However, concerns have been raised that their growing use may result in bacteria that are less susceptible. Methods: The capacity of common antiseptics such as silver nitrate, polihexanide, octenidine, chlorhexidine and polyvinylpyrrolidone (PVP)-iodine to induce adaptation in a Staphylococcus aureus strain was analyzed in vitro using microplate laser nephelometry. S. aureus was repeatedly incubated with the respective half maximal inhibitory concentration $\left(\mathrm{IC}_{50}\right)$ over a time period of 100 days. The influence of the continued treatment was determined by in situ monitoring of changes in the dose-response curves and calculation of the current $\mathrm{IC}_{50}$ values for the substances tested. Results: During the experiment, S. aureus quickly adapted to high concentrations of the antibiotic mu-
\end{abstract}

\section{KARGER}

E-Mail karger@karger.ch www.karger.com/spp
(C) 2012 S. Karger AG, Basel $1660-5527 / 12 / 0256-0288 \$ 38.00 / 0$

Karger
Open access

This is an Open Access article licensed under the terms of the Creative Commons Attribution- NonCommercial-NoDerivs 3.0 License (www.karger.com/OA-license), applicable to the online version of the article only. Distribution for non-commercial purposes only. pirocin during repeated treatment. Moreover, a significant increase of the $\mathrm{IC}_{50}$ for silver nitrate was observed over time. On the other hand, no significant difference was observed for polihexanide or chlorhexidine. While the $\mathrm{IC}_{50}$ for octenidine was also found to increase significantly, although the change was only marginal, reiterated incubation with PVPiodine led to a decrease in the $\mathrm{IC}_{50}$. Conclusion: Repeated treatment of S. aureus with polihexanide, chlorhexidine, octenidine and PVP-iodine did not trigger bacterial adaptation to these substances.

Copyright $\odot 2012$ S. Karger AG, Basel

\section{Introduction}

Bacterial colonization and infection are important factors in compromised wound healing. A high bioburden can disrupt the regular healing sequence and result in a chronic inflammatory wound, which leads to cellular dysfunction and biochemical imbalance [1]. Antibiotics are often used to battle infection. However, the widespread application of systemic and topical antibiotics is associated with the emergence of resistant bacterial strains such as methicillin-resistant Staphylococcus aureus (MRSA). Therefore, antiseptics have become a criti- 
cal alternative for antimicrobial applications. Increasing numbers of products containing antimicrobial agents are manufactured to enhance the management of microorganisms in the healthcare environment. In addition, they can be found in cosmetics and a number of other products such as sports underwear, shower curtains, door handles, bed linen, trolleys, washing up liquid, etc. Hence, the question has been raised whether this increasing usage should be of genuine concern due to the possible development of antiseptic-resistant germs [2].

There are two major mechanisms of resistance, intrinsic and acquired resistance. An intrinsic nonsusceptibility means that an antiseptic is unable to reach its target site in adequately high amounts to achieve a biocidal effect. This includes, for example, a change in cell wall properties, loss or alteration of porins, surface hydrophobicity, or the presence of efflux pumps [2,3]. Additionally, physiological (phenotypic) adaptation can modulate the intrinsic resistance, e.g. of cells contained within a biofilm. By contrast, acquired resistance results from genetic changes in a bacterial cell and arises by mutation or by the acquisition of plasmids or transposons [4]. Unlike antibiotics, which act selectively on a specific target, antiseptics have multiple targets with a broad spectrum of activity. Hence, the risk for the development of nonsusceptibility should be low. However, microorganisms can adopt strategies to counter toxic environments [5]. So far, bacterial resistance to organic cationic compounds such as chlorhexidine and quaternary ammonium compounds $[4,6]$, as well as to silver $[7,8]$, have been described.

In vitro investigations help to clarify and to highlight the mechanisms of bacterial resistance. It has been shown that bacteria can adapt to harmful agents by decreasing their cytoplasmic concentrations through various mechanisms [2]. In addition, in vitro experiments allow the investigation of the capacity of the antiseptics to induce adaptation in bacteria in a controlled and reproducible manner. Several techniques have been used to 'train' bacteria like S. aureus or Escherichia coli to develop resistance to antiseptics, such as disc diffusion, stepwise preparation in broth, repeated exposure to sublethal concentrations, or growth in a basal medium plus an antimicrobial agent $[9,10]$. In the present study, S. aureus, which is almost universally present in chronic wounds [11], has been used as a model organism to investigate the adaptation capacity of bacteria to various antiseptics using microplate laser nephelometry (MLN). MLN can be used to monitor the growth of microorganisms by the turbidity of the respective medium. While turbidimetry itself requires relatively high concentrations of particles and obeys Beer's Law, nephelometry is a direct method of measuring light scattered by particles in solution at a right or forward angle to a laser beam. The most common application of laser-based nephelometry in microplate format is the fully automated solubility screen in highthroughput screening laboratories [12]. Nephelometry is further used in clinical chemistry to determine serum immunoglobulin (IgA, IgG, IgM), complement components $(\mathrm{C} 3, \mathrm{C} 4)$, acute phase reactant proteins (CRP, transferring), albumin, and $\alpha-1$-antitrypsin by protein precipitation, or in organic chemistry to quantify macromolecules, e.g. monitoring of a polymerization reaction. In addition, MLN can be used to study the effect of antimicrobial substances on the growth of microorganisms [13, 14]. Compared to other methods used $[9,15]$, MLN enables high-throughput screening of several antiseptics and repetition over a prolonged time period, e.g. 100 days. Furthermore, possible changes in the MIC can only be determined for most techniques retrospectively while MLN allows in situ recording of dose-response curves and simultaneous monitoring of alterations in the $\mathrm{IC}_{50}$, a parameter that would be affected if bacteria adapted to the antiseptics. Although disc diffusion methods may offer the possibility of observing changes in situ, it depends on the diffusion capacity of the active agent tested. Large molecules such as polihexanide may have a reduced ability to disperse through the agar compared to small molecules, thus influencing the test outcome. As MLN investigations are performed in solution they do not depend on the diffusion capacities of the substances.

The growth of $S$. aureus under increasing concentrations of the following antiseptics: polihexanide, octenidine, silver nitrate, chlorhexidine and polyvinylpyrrolidone (PVP)-iodine, was monitored by MLN, and $\mathrm{IC}_{50}$ concentrations were calculated from the dose-response curves. For comparison, the antibiotic mupirocin was also tested in the study. Further, S. aureus was repeatedly incubated with the respective $\mathrm{IC}_{50}$ concentrations over a time period of 100 days. The influence of the continued treatment was determined by the calculation of the current $\mathrm{IC}_{50}$ values for mupirocin and the antiseptics tested.

\section{Materials and Methods}

Materials

The following antiseptics have been used in this study: silver nitrate $\left(\mathrm{AgNO}_{3}\right.$, ACS reagent $\geq 99 \%$, Sigma), polihexanide (Cosmocil ${ }^{\circledR}$ CQ $20 \%$ polyhexamethylene biguanide, PHMB, Arch Chemicals, USA), chlorhexidine (chlorhexidine digluconate solution, $20 \%$ in $\mathrm{H}_{2} \mathrm{O}$, Sigma), octenidine (Octenisept ${ }^{\circledR}, 0.1 \%$ octeni- 
Table 1. $\mathrm{IC}_{50}$ values of the antiseptics compared to mupirocin before and after treatment of $S$. aureus

\begin{tabular}{lllll}
\hline Substance & $\begin{array}{l}\text { Concentra- } \\
\text { tion range }\end{array}$ & $\begin{array}{l}\text { Initial } \\
\mathrm{IC}_{50}\end{array}$ & $\begin{array}{l}\mathrm{IC}_{50} \text { after } \\
100 \text { days }\end{array}$ & Slope \\
\hline Mupirocin, $\mathrm{ng} / \mathrm{ml}$ & $1-500$ & 12.5 & $103.6^{* * *}$ & $1.1^{* * *}$ \\
Silver nitrate, $\mu \mathrm{g} / \mathrm{ml}$ & $1-40$ & 5.3 & $10.8^{* * *}$ & $0.06^{* * *}$ \\
Polihexanide, $\mu \mathrm{g} / \mathrm{ml}$ & $0.1-10$ & 0.53 & $0.48 \mathrm{NS}$ & $<0.001$ \\
Chlorhexidine, $\mu \mathrm{g} / \mathrm{ml}$ & $0.1-10$ & 0.56 & $0.63 \mathrm{NS}$ & $<0.001$ \\
Octenidine, $\mu \mathrm{g} / \mathrm{ml}$ & $0.2-1.2$ & 0.51 & $0.63^{*}$ & $<0.001$ \\
PVP-iodine, $\mathrm{mg} / \mathrm{ml}$ & $0.25-3$ & 0.93 & $0.62^{*}$ & $-0.003^{* *}$ \\
\end{tabular}

The changes in the $\mathrm{IC}_{50}$ values can be expressed as the slope of the linear regression. NS $=$ Not significant. Differences to the other substances tested: ${ }^{*} \mathrm{p}<0.05 ;{ }^{* *} \mathrm{p}<0.01 ;{ }^{* * *} \mathrm{p}<0.001$.

dine dihydrochloride, Schülke \& Mayr GmbH, Germany), and PVP-iodine complex (Sigma). The antibiotic mupirocin $(\geq 95 \%$ HPLC; Sigma) was used for comparison.

The wound dressings Suprasorb ${ }^{\circledR} \mathrm{X}+\mathrm{PHMB}$ and Suprasorb ${ }^{\circledR}$ A+Ag were allocated by Lohmann \& Rauscher GmbH and Co. KG (Germany). Other wound dressings tested were obtained from their manufacturers: Kerlix AMD and Covidien AMD (Tyco Healthcare Ltd., UK), Aquacel Ag (ConvaTec GmbH, Germany), Acticoat Absorbent (Smith \& Nephew Ltd., UK), as well as Urgotül Silver, Urgosorb Silver, and Urgocell Silver (Laboratoires Urgo, France).

S. aureus ATCC 6538 was purchased from the DSMZ (Deutsche Sammlung von Mikroorganismen und Zellkulturen, Germany). For the cultivation of bacteria, special peptone and 'Lab-Lemco' powder for the preparation of Caso-Bouillon were obtained from Oxoid (UK). Columbia agar plates with $5 \%$ sheep blood were purchased from BioMérieux (France). $\mathrm{NaCl}$ solution was obtained from Fresenius Kabi Deutschland GmbH (Germany) and Tween 20 was purchased from Roth (Germany).

\section{Microplate Laser Nephelometry}

Caso-Bouillon $(20 \mathrm{ml})$ was inoculated with 1-2 colonies of $S$. aureus grown on Columbia agar plates and incubated for $24 \mathrm{~h}$ at $37^{\circ} \mathrm{C}$ under shaking. The resulting cell suspension was diluted $1: 10^{5}$ in serial steps, yielding a working suspension of approximately $5 \times 10^{3}$ colony-forming units (CFU)/ml. Of this suspension, $100 \mu \mathrm{l}$ was put in the respective wells of the 96-well microplate containing the prepared dilutions of the antiseptics. Serial dilutions of the test substances were prepared in Caso-Bouillon (for concentration ranges refer to table 1). A hundred microliters each were put in triplicate into the respective wells of a sterile, clear, 96-well microplate (Greiner Bio-One, Germany). Blanks for each substance concentration tested were run at every assay. The microplates were covered with a clear adhesive film (Greiner BioOne). The adhesive film was punctured with a 25 -gauge needle at the right brim of the well to allow gas exchange. The microplates were then placed in the microplate laser nephelometer (NEPHELOstar Galaxy, BMG Labtech, Germany) and incubated for $24 \mathrm{~h}$ at $37^{\circ} \mathrm{C}$. During incubation the microplates were shaken in the instrument, except for the duration of the hourly measurement.
The half maximal inhibitory concentration $\left(\mathrm{IC}_{50}\right)$ of the antiseptics under the experimental conditions used was calculated from the growth curves over $24 \mathrm{~h}$. The area under the curve was determined from the results for each antiseptic concentration tested and calculated as a percentage of the untreated control. This was used to realize a dose-response curve for each antiseptic tested, from which the $\mathrm{IC}_{50}$ was calculated using a logistic fit function $\left[\mathrm{y}=\mathrm{A} 2+(\mathrm{A} 1-\mathrm{A} 2) /\left(1+[\mathrm{x} / \mathrm{x} 0]^{\mathrm{p}}\right) ; \mathrm{A} 1=\right.$ upper limit, $\mathrm{A} 2=$ lower limit, $\mathrm{x} 0=\mathrm{IC}_{50}, \mathrm{p}=$ slope of the curve; Origin 7.5; OriginLab, USA].

\section{Development of Adaptation}

To investigate whether S. aureus is able to adapt to the antiseptics or not, the bacteria were repeatedly incubated with the $\mathrm{IC}_{50}$ concentrations of the respective antiseptic followed by nephelometric determination of the current $\mathrm{IC}_{50}$. For this, $20 \mathrm{ml}$ CasoBouillon was inoculated with $500 \mu$ l of the $S$. aureus incubated with the $\mathrm{IC}_{50}$ concentration of the respective antiseptic from the MLN measurement (samples from the triplicate preparation were pooled beforehand). Bacteria suspensions were incubated for $24 \mathrm{~h}$ at $37^{\circ} \mathrm{C}$ under shaking and afterwards diluted $1: 10^{5}$ in serial steps, yielding a working suspension of approximately $5 \times 10^{3} \mathrm{CFU} / \mathrm{ml}$. $100 \mu \mathrm{l}$ of these suspensions were put in the respective wells of the 96-well microplates containing the prepared antiseptic dilutions as described (for concentration ranges refer to table 1). MLN measurement and calculation of the current $\mathrm{IC}_{50}$ were performed, as explained earlier. Exposure to the respective $\mathrm{IC}_{50}$ concentrations of the antiseptics (refer to table 1 for initial $\mathrm{IC}_{50}$ ) following this protocol was repeated for 100 days. For each substance tested twelve independent experiments were performed.

Identification of S. aureus by MALDI-TOF Mass Spectrometry Adapted $S$. aureus strains were grown on Columbia agar plates for $24 \mathrm{~h}$ at $37^{\circ} \mathrm{C}$. The plates were then sealed and sent to AnagnosTec $\mathrm{GmbH}$ (Germany) for identification. Individual colonies were removed from the plates using a sterile pipette tip and prepared for matrix-assisted laser desorption/ionization and timeof-flight (MALDI-TOF) mass spectrometry as described [16]. All mass spectra were acquired with an Ultraflex II MALDI-TOF/ TOF mass spectrometer (Bruker Daltonics, Germany) equipped with an all-solid-state smart beam Nd:YAG laser and operated at $100 \mathrm{~Hz}$ in the positive linear mode. Each spectrum was obtained by averaging up to 10,000 laser shots acquired at the minimum laser power necessary for ionization of the samples. Data was evaluated by matching the MALDI-TOF fingerprint mass spectra obtained against reference spectra for $S$. aureus from the SARAMIS database (AnagnosTec $\mathrm{GmbH}$ ).

\section{Determination of Antibacterial Activity against}

Silver-Nitrate-Adapted and Polihexanide-Treated S. aureus

The determination of antimicrobial activity was performed according to the internationally recognized Japanese Industrial Standard (JIS L 1902:2002) testing method for antibacterial activity of textiles [17]. Caso-Bouillon $(20 \mathrm{ml})$ was inoculated either with a silver-nitrate-adapted or a polihexanide-adapted S. aureus strain from this study and cultivated for $24 \mathrm{~h}$ at $37^{\circ} \mathrm{C}$. For the experiments, $400-\mathrm{mg}$ samples of the wound dressings were incubated with each test microbe $(200 \mu \mathrm{l})$ for $24 \mathrm{~h}$ at $37^{\circ} \mathrm{C}$. Samples of polyester material were used as control; they are known not to inhibit microbial growth. For bacteria quantification the incu- 


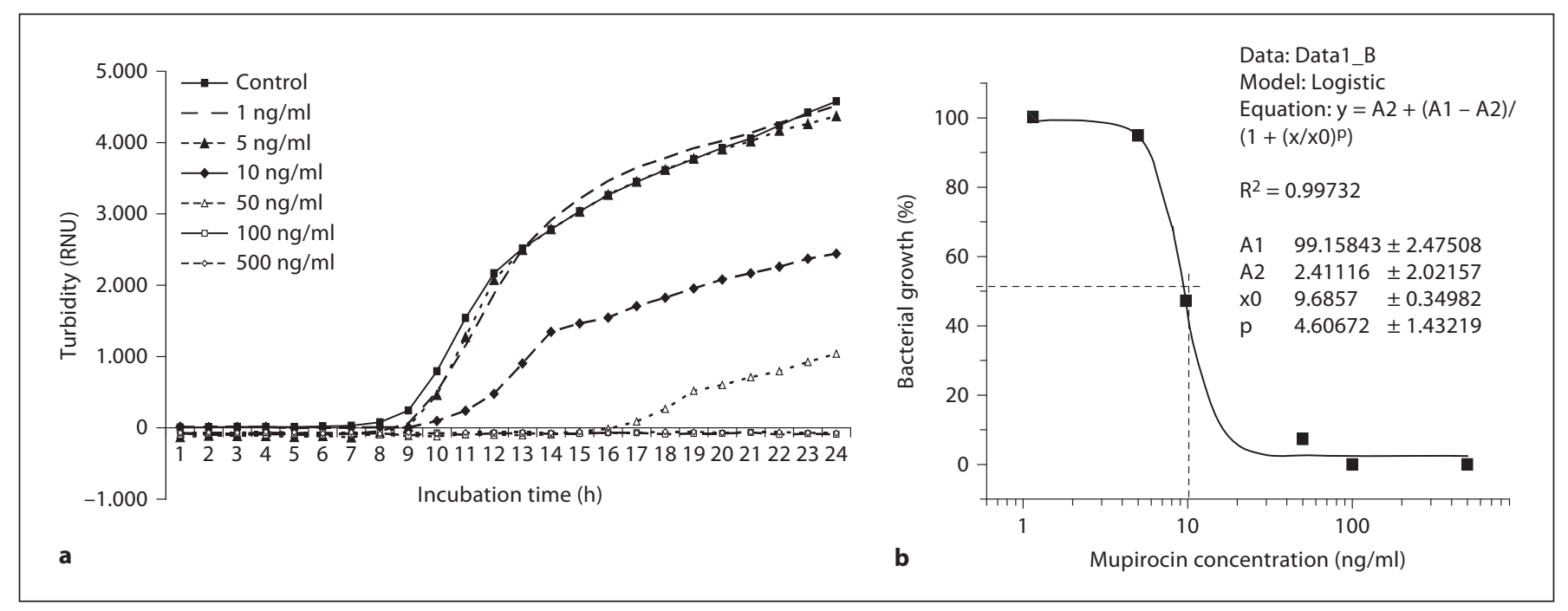

Fig. 1. Growth curves of $S$. aureus under increasing concentrations of mupirocin measured as turbidity of the solution by MLN in RNU (relative nephelometric units) (a). Low concentrations did not affect bacterial growth, while high concentrations exerted a bacteriostatic or bactericidal effect, discernible by the absence of

bated samples were extracted in a $10-\mathrm{ml} 0.9 \% \mathrm{NaCl}$ solution with Tween 20. Serial dilutions were plated on Columbia agar plates, incubated for $24 \mathrm{~h}$ at $37^{\circ} \mathrm{C}$ and the colonies counted afterwards. The CFU/ml and the total microbial count of the samples (in CFU) were calculated. The growth reduction compared to the starting value was determined according to [17]:

$$
\text { growth reduction }(\log \mathrm{CFU})=\log \left[{ }^{24} \mathrm{~h} \mathrm{MW}(\mathrm{CFU})_{\text {control }}\right]-
$$$$
\log \left[{ }^{24} \mathrm{hW}(\mathrm{CFU})_{\text {sample }}\right] \text {. }
$$

The rating was: no antimicrobial activity $=<0.5 \log$ microbial growth reduction; slight antimicrobial activity $=0.5-1 \log$ microbial growth reduction; significant antimicrobial activity $=>1$ to $\leq 3 \log$ microbial growth reduction; strong antimicrobial activity $=>3 \log$ microbial growth reduction.

\section{Statistics}

All values cited are expressed as means \pm standard error. One-way analysis of variance was carried out to determine statistical significances (Microsoft ${ }^{\circledR}$ Excel 2000). Differences were considered statistically significant at a level of $\mathrm{p}<0.05$.

\section{Results}

S. aureus was incubated with increasing concentrations of the antibiotic mupirocin. Whilst low concentrations did not affect bacterial growth, high concentrations exerted a bacteriostatic or bactericidal effect, discernible by the absence of intensification in turbidity (fig. 1a). From these results, the $\mathrm{IC}_{50}$ of mupirocin was calculated intensification in turbidity. The $\mathrm{IC}_{50}$ was calculated from the growth curve results according to a logistic fit function (b). $\mathrm{R}^{2}=$ Coefficient of determination; A1 = upper limit; A2 = lower limit; $\mathrm{x} 0=\mathrm{IC}_{50} ; \mathrm{p}=$ slope of the curve.

using a logistic fit function (fig. 1b). Similarly, the growth curves for $S$. aureus with the antiseptics, silver nitrate, polihexanide, octenidine, chlorhexidine and PVP-iodine were recorded by MLN and the $\mathrm{IC}_{50}$ values were calculated (table 1).

$S$. aureus was further repeatedly incubated with the respective $\mathrm{IC}_{50}$ concentrations over a time period of 100 days. The effect of this treatment with mupirocin and the antiseptics on $S$. aureus was measured every other day by the determination of the current $\mathrm{IC}_{50}$ using MLN. Figure 2 shows the development of the dose-response curves after 20, 40, 60, 80 and 100 days. S. aureus showed a distinct and fast adaptation to the antibiotic mupirocin, resulting in an increase of the $\mathrm{IC}_{50}$ over time (fig. 3a). The $\mathrm{IC}_{50}$ value for silver nitrate was also found to significantly increase during repeated treatment (fig. 3b). On the other hand, polihexanide, octenidine, chlorhexidine and PVPiodine showed a much lower potency to induce adaptation in S. aureus (fig. 3c-f). In fact, repeated treatment with PVP-iodine even resulted in more susceptible germs. The comparison of the initial $\mathrm{IC}_{50}$ values and those after treatment for 100 days is shown in table 1 .

The changes in the $\mathrm{IC}_{50}$ values can be expressed as the slope of the linear regression. The antibiotic mupirocin demonstrated a significantly higher slope than the antiseptics tested (table 1), indicating a high risk for the emergence of resistance. From the antiseptics, only sil- 


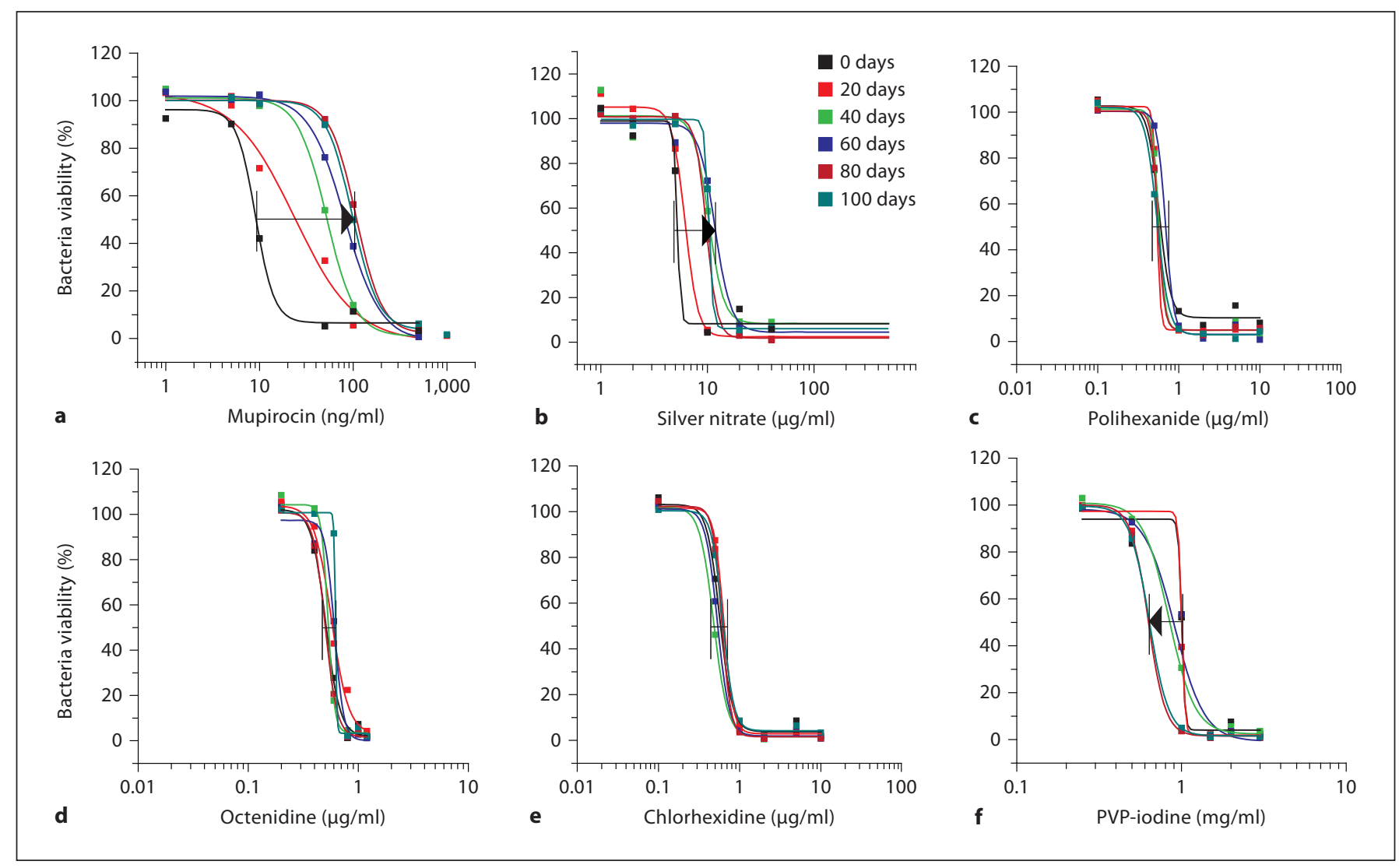

Fig. 2. Development of the dose-response curves after 20, 40, 60, 80 and 100 days for $S$. aureus repeatedly incubated with mupirocin (a), silver nitrate (b), polihexanide (c), octenidine (d), chlorhexidine (e) and PVP-iodine (f). Mupirocin curves show a distinct and fast adaptation of $S$. aureus to high concentrations of the an- tibiotic. Furthermore, a change to higher concentrations was found for silver nitrate. No alterations were observed for polihexanide, octenidine and chlorhexidine, while a shift to lower concentrations was obtained for PVP-iodine. ver nitrate showed a slope that was significantly higher compared to polihexanide, octenidine, chlorhexidine and PVP-iodine. This indicates a distinct risk of developing adaptation to silver when low concentrations are used in a clinical setting. No significant change in the $\mathrm{IC}_{50}$ values could be noted for polihexanide and chlorhexidine, with slope values less than 0.001 . Octenidine showed a statistically significant increase of the $\mathrm{IC}_{50}$ after 100 days; however, the slope value was less than 0.001 . The $\mathrm{IC}_{50}$ of PVP-iodine significantly decreased during treatment and the slope was -0.003 .

To ensure that changes in the behavior of $S$. aureus towards the antibiotic and antiseptics tested really occurred by adaptation and were not due to contamination with other microorganisms during the experiment, the treated $S$. aureus strains were analyzed by MALDI-TOF mass spectrometry. All probes were identified as $S$. aureus spe- cies by this method, with an accuracy of $99.9 \%$ (fig. 4). Hence, all changes observed can be attributed to alterations in the adapted S. aureus strains.

Antimicrobials are increasingly utilized in wound dressings for the treatment of infected or critically colonized chronic wounds. Several dressings containing silver ions or polihexanide are available for this purpose. A test was done to determine if the in vitro adaptation of $S$. aureus to silver nitrate or treatment with polihexanide affects the antibacterial efficacy of these wound dressings. Hence, silver- and polihexanide-containing dressings were tested for their antimicrobial activity against the native $S$. aureus strain, as well as a silver-nitrateadapted and a polihexanide-treated $S$. aureus strain from this study. Polihexanide-containing wound dressings achieved a strong reduction of the bacterial growth in the case of the native as well as the polihexanide-treated $S$. 


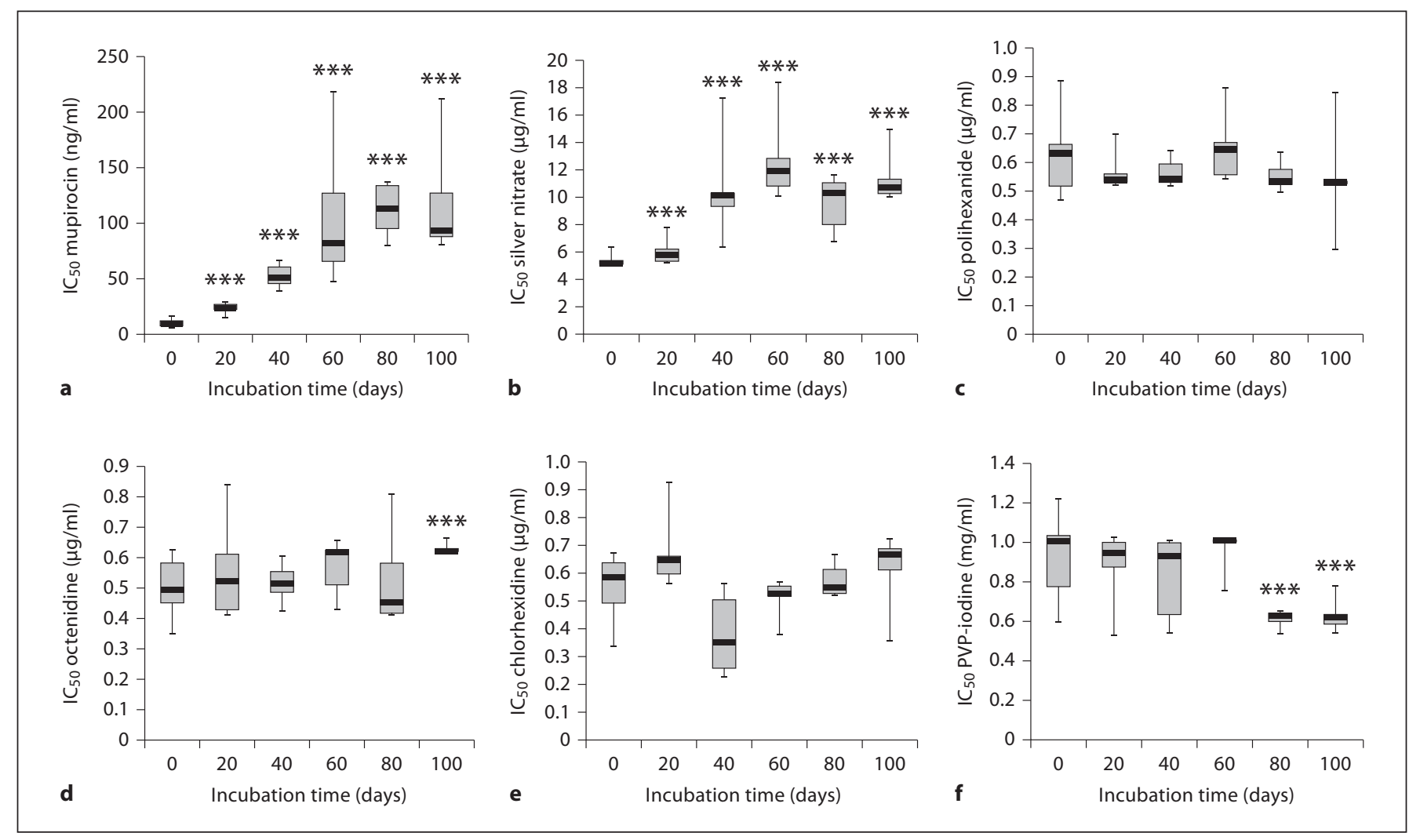

Fig. 3. Changes in the $\mathrm{IC}_{50}$ values of mupirocin (a), silver nitrate (b), polihexanide (c), octenidine (d), chlorhexidine (e) and PVPiodine (f) during the repeated treatment of $S$. aureus over a time period of 100 days. $\mathrm{IC}_{50}$ values for mupirocin and silver nitrate significantly increased, while polihexanide, octenidine, chlorhex- idine and PVP-iodine showed a much lower potency to induce adaptation in $S$. aureus. Data presented are median (black bar), upper and lower quartile (grey box), and 95\% confidence interval (whiskers) at 0, 20, 40, 60, 80 and 100 days. Asterisks indicate significant difference to $\mathrm{IC}_{50}$ at day $0\left({ }^{* * *} \mathrm{p}<0.001\right)$. aureus (fig. 5a). Differences in the antibacterial efficacy of the various silver-containing dressings studied were observed. However, all dressings tested showed a similar bactericidal effect against the native and the silver-nitrate-adapted S. aureus strain (fig. 5b).

\section{Discussion}

Antiseptics for wound treatment are chosen by (a) how safe and (b) how effective they are. The safety is determined by the influence on the wound's healing progress, e.g. if it is delayed or even inhibited. The efficacy is mainly concluded from its microbicidal activity and its ability to decrease wound infection. However, it is also important to test the products used for their potential to induce bacterial resistance or adaptation during prolonged exposure.

S. aureus - Adaptation to Antiseptics
Mupirocin (pseudomonic acid A), is a polyketide antibiotic with a narrow spectrum against Gram-positive bacteria, particularly staphylococci, including MRSA. It impairs bacterial protein synthesis by binding to isoleucyl-tRNA synthetase and preventing the incorporation of isoleucine into a growing polypeptide chain. Its extensive use in MRSA patients has been followed by a rapid emergence of mupirocin-resistant strains [18, 19]. Using MLN to detect the adaptation of $S$. aureus to mupirocin, a fast and highly significant increase in the $\mathrm{IC}_{50}$ of the antibiotic was observed. This most likely confers a true resistance, although genetic characterization was not performed. Two catagories of mupirocin resistance have been described for S. aureus. Most isolates with a high-level resistance have obtained plasmid-mediated mupA, which encodes a novel isoleucyl-tRNA synthetase [19]. Low-level resistance to the antibiotic arises by mutation in the native isoleucyl-tRNA synthetase gene ileS [2, 


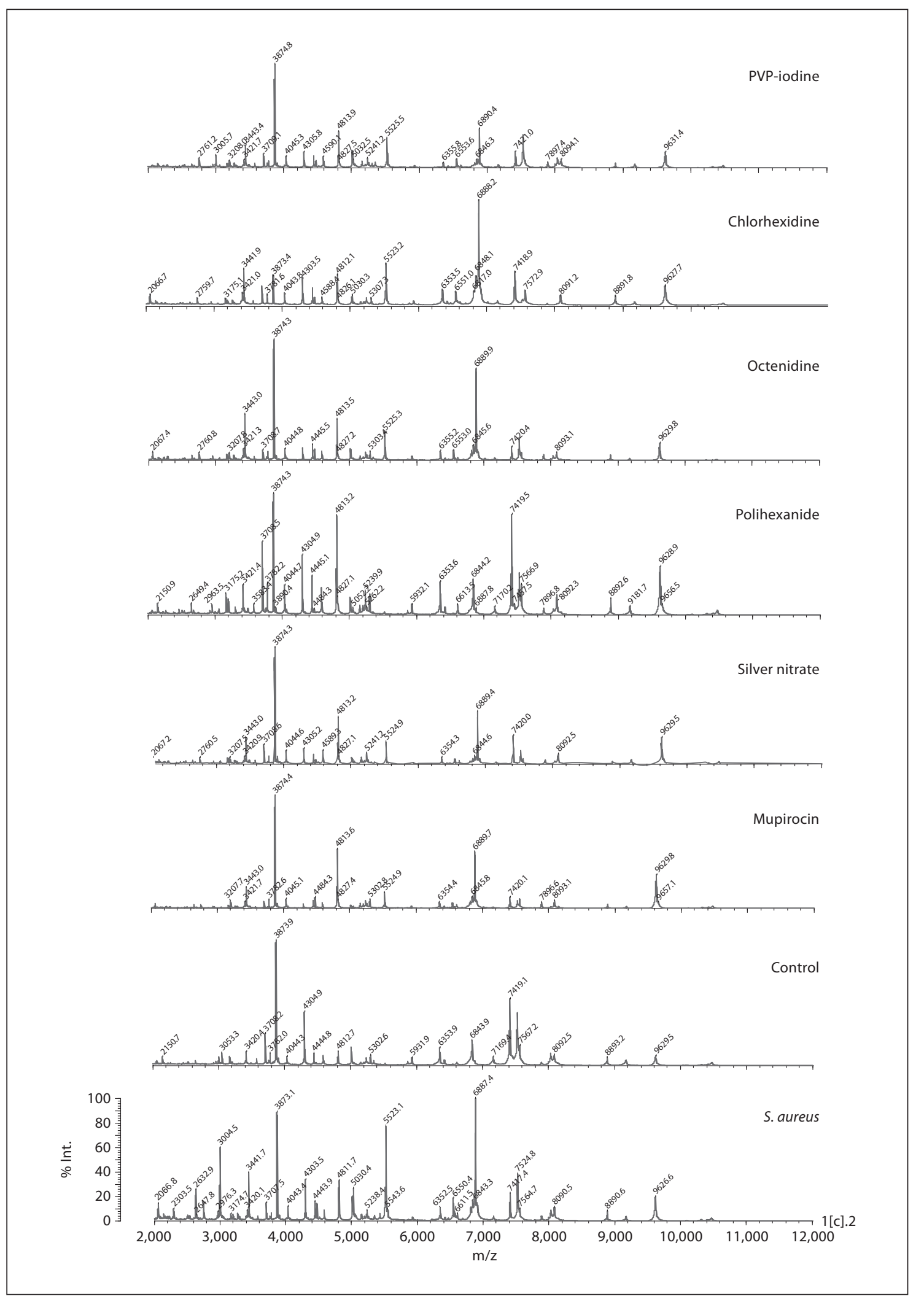

Fig. 4. Analysis of untreated S. aureus and the treated strains by MALDI-TOF for species confirmation. All probes were identified as $S$. aureus with an accuracy of $99.9 \%$.

294

Skin Pharmacol Physiol 2012;25:288-297

Wiegand/Abel/Ruth/Hipler 

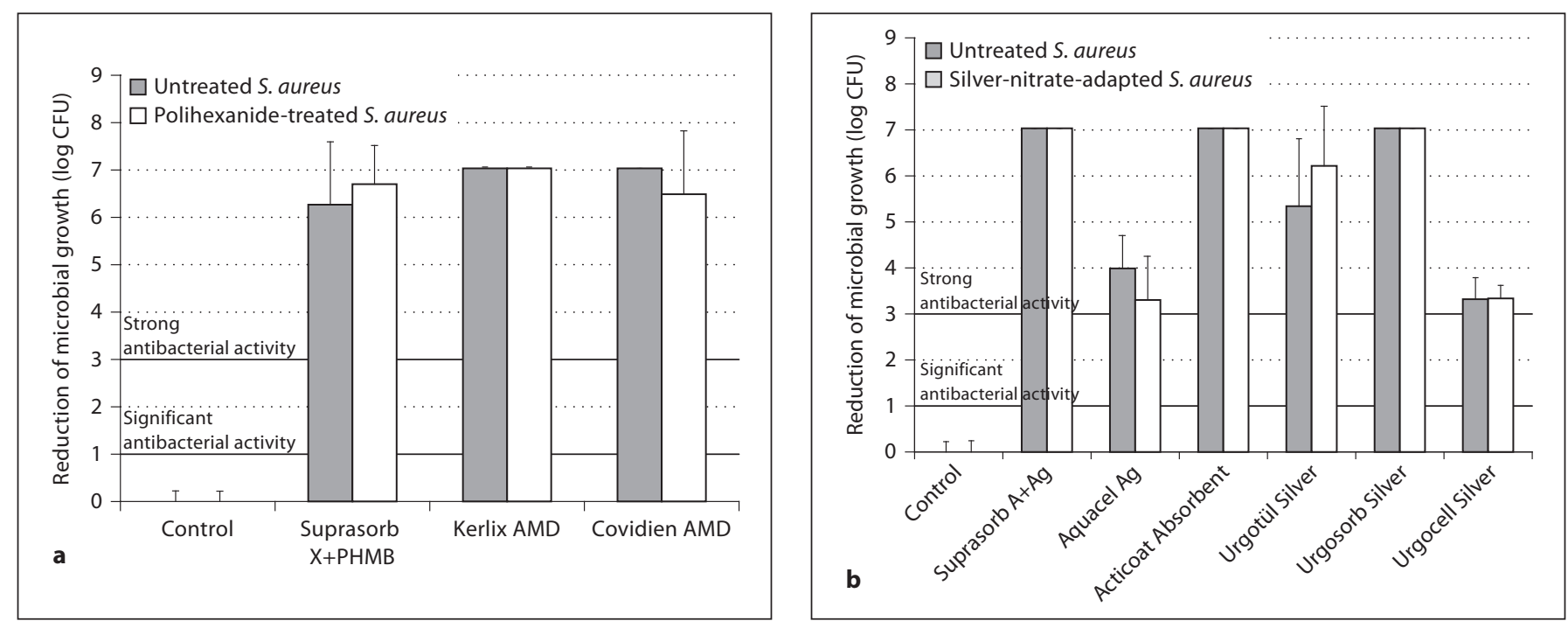

Fig. 5. Determination of the antibacterial activity of polihexanide-containing wound dressings (a) and silverbased products (b) on native and treated S. aureus. No differences in the antibacterial efficacy were observed.

$20,21]$. It is presumed that the changes observed in this study refer to a low-level resistance.

Unlike the antibiotic mupirocin, silver $\left(\mathrm{Ag}^{+}\right)$works on multiple components of bacterial cell metabolism. Silver ions react with inorganic compounds, organic acids, proteins, DNA and RNA, killing the microorganisms through the inhibition of cellular respiration, interference with DNA replication and alteration of cellular membrane permeability [8]. The commonly used forms are silver-coated dressings that are more effective at killing a broader range of bacteria than cream-based silver applications and are less irritating than silver nitrate solutions [22]. However, concerns are being raised due to the overuse of silver and the consequent emergence of bacterial resistance. Resistance may develop if the concentration of silver is not high enough to exert a bactericidal effect. As maintaining an adequate concentration of active silver ions over time is a challenge, silver resistance is very possible [8]. Molecular genetics of silver resistance show that it can be conferred by plasmids encoding efflux pumps or silver-binding proteins [7]. However, the probability for the transfer of silver resistance genes seems to be low, unstable and difficult to maintain [23]. Using the MLN method, a slight adaptation of $S$. aureus to silver nitrate could be detected and confirmed by a significant increase of the $\mathrm{IC}_{50}$. However, the antibacterial activity of silver dressings was not found to be altered. This is in accordance with a study by Loh et al. [24] showing that
MRSA isolates carrying silver resistance genes remained susceptible to silver dressings. Hence, differences in the effects of silver-containing dressings against $S$. aureus probably depend on the silver content present and the delivery form of the active silver ion [22].

It could be shown that the positively charged antiseptics, polihexanide, chlorhexidine and octenidine do not induce adaptation during continuous treatment in vitro. These cationic, surface-active substances are effective against a broad spectrum of microorganisms, including Gram-positive and Gram-negative bacteria [25-28]. They interact with negatively charged molecules in the bacterial cell membranes, resulting in their disruption. It could be shown that polihexanide induces aggregation of acidic lipids in the vicinity of the adsorption site. This changes the membrane permeability and may alter the function of membrane-associated enzymes, causing leakage of cytoplasmatic compounds such as $\mathrm{K}^{+}$[26]. Moreover, the increased permeability of the cell wall allows small molecules like chlorhexidine to penetrate into the bacteria cell and act on targets within the bacteria [27]. Hence, its application for decolonization strategies preventing the transmission of MRSA in intensive care units has been suggested [27]. However, Pseudomonas aeruginosa strains exhibiting raised MIC to chlorhexidine have been observed [29] and MRSA strains with decreased susceptibility have been frequently isolated from clinical settings $[30,31]$. While other studies also reported the develop- 
ment of resistance towards chlorhexidine [32, 33], this was not found in the present study. Although a slight increase in the $\mathrm{IC}_{50}$ was noted, the change was statistically not significant. However, the unsuccessful induction of resistance to chlorhexidine is in accordance with studies by Karen et al. [34] and Suller and Russell [9]. Furthermore, Thomas et al. [29] showed that $P$. aeruginosa strains exhibiting raised MIC to chlorhexidine were no less sensitive to the agent than the parent strain. Hence, an increase in the MIC for an antiseptic in vitro does not necessarily cause a failure in eradicating the microorganisms in vivo. This is most likely due to the higher concentrations used in practice for disinfection [29].

Studies of Seipp and Körber [35], using the agar diffusion test, and Al-Doori et al. [36], employing five different MRSA clones, also showed that polihexanide and octenidine do not trigger the acquisition of resistance. It can be assumed that these cationic antiseptics do not cause bacterial adaptation due to their multiple target sites and the electrostatic interactions.

PVP-iodine is a complex of polyvinylpyrrolidone and triiodine ions that is widely used as an antiseptic in trauma and orthopedic surgery. The microbicidal spectrum is broad and only short exposure times are needed [37]. Furthermore, PVP-iodine shows high bactericidal activity against resistant bacteria strains, e.g. MRSA or Enterococcus faecium [37] and it was shown that it does not induce adaptation in bacteria [32]. In fact the results presented here prove that repeated treatment with PVP-iodine even led to a more susceptible $S$. aureus strain in vitro. It is further effective against biofilm formation [32], even in subinhibitory concentrations [38]. Hence, PVP-iodine could be of interest for new applications in decontamination regimens or in the treatment of infected body cavities and joints [37]. However, its application in wound treatment remains controversial, as it may have potential systemic side effects and exert possible cytotoxic effects leading to impaired wound healing $[39,40]$.

In conclusion, concerns have been raised that the increasing use of antiseptics may result in bacteria that are less susceptible. MLN presents a valuable tool to investigate bacterial adaptation to antiseptics as it allows highthroughput screening, incubation over a prolonged time period, and in situ monitoring of changes in the doseresponse curves. Employing MLN, it could be shown that S. aureus quickly adapts to high concentrations of the antibiotic mupirocin during repeated treatment. This clearly indicates that last-resort antibiotics should be used cautiously to ensure their effect on challenging germs such as MRSA, which are resistant to generally used antibiotics. Commonly used antiseptics showed a much lower potency to induce adaptation in $S$. aureus. Only the $\mathrm{IC}_{50}$ for silver nitrate was found to significantly increase during treatment. Although silver-containing wound dressings were still as effective against the silver-adapted $S$. aureus in this study, the results indicate that an overuse of silver in consumer products may raise future problems. However, polihexanide, chlorhexidine, octenidine and PVPiodine did not trigger resistance in the microbes, presenting themselves as promising alternatives for antimicrobial treatment in the healthcare environment.

\section{Acknowledgements}

This work was supported by Lohmann \& Rauscher $\mathrm{GmbH}$ and Co. KG, Rengsdorf, Germany.

The authors would like to thank Doreen Winter for her excellent technical assistance on the MLN and Marcel Ehrhard for performing the MALDI-TOF mass spectrometry analysis.

\section{References}

1 Kingsley A: The wound infection continuum and its application to clinical practice. Ostomy Wound Manage 2003;49(suppl 7A):1-7.

2 Maillard J-Y: Bacterial resistance to biocides in the healthcare environment: should it be of genuine concern? J Hosp Infect 2007;65: $60-72$.

-3 Malaviolle X, Nonhoff C, Denis O, Rottiers S, Struelens MJ: Evaluation of disc diffusion methods and Vitek 2 system for testing susceptibility to mupirocin in Staphylococcus aureus. J Antimicrob Chemother 2008;62: 1018-1023.
4 Russell AD: Bacterial resistance to disinfectants: present knowledge and future problems. J Hosp Infect 1998;43(suppl):S57-S68.

5 Sheldon AT Jr: Antiseptics 'resistance': real or perceived threat? Clin Infect Dis 2005;40: 1650-1656.

6 Russell AD: Plasmids and bacterial resistance to biocides. J Appl Microbiol 1997;82: 155-165.

7 Silver S: Bacterial silver resistance: molecular biology and uses and misuses of silver compounds. FEMS Microbiol Rev 2003;27: 341-353.
8 Warriner R, Burrell R: Infection and the chronic wound: a focus on silver. Adv Skin Wound Care 2005;18(suppl 1):2-12.

9 Suller MT, Russell AD: Antibiotic and biocide resistance in methicillin-resistant Staphylococcus aureus and vancomycin-resistant Enterococcus. J Hosp Infect 1999;43: 281-291.

10 Wiegand C, Abel M, Kramer A, Müller G, Ruth P, Hipler U-C: Proliferationsförderung und Biokompatibilität von Polihexanid. GMS Krankenhaushyg Interdiszip 2007; 2: $\operatorname{doc} 43$. 
11 Kirketerp-Moller K, Jensen PO, Fazli M, Madsen KG, Pedersen J, Moser C, TolkerNielsen T, Hoiby N, Giuskov M, Bjarnsholt T: Distribution, organization, and ecology of bacteria in chronic wounds. J Clin Microbiol 2008;46:2717-2722.

12 Bevan CD, Llyod RS: A high-throughput screening method for the determination of aqueous drug solubility using laser nephelometry in microtiter plates. Anal Chem 2000;72:1781-1787.

-13 Fouda MMG, Knittel D, Hipler U-C, Elsner P, Schollmeyer E: Antimycotic influence of $\beta$-cyclodextrin complexes - in vitro measurements using laser nephelometry in microtiter plates. Int J Pharm 2006;311:113121.

14 Seyfarth F, Schliemann S, Elsner P, Hipler U-C: Antifungal effect of high- and low-molecular-weight chitosan hydrochloride, carboxymethyl chitosan, chitosan oligosaccharide and $\mathrm{N}$-acetyl-D-glucosamine against candida albicans, candida krusei and candida glabrata. Int J Pharm 2008;353:139-148.

15 Walsh SE, Maillard J-Y, Russell AD, Catrenich CE, Charbonneau DL, Bartolo RG: Development of bacterial resistance to several biocides and effects on antibiotic susceptibility. J Hosp Infect 2003;55:98-107.

16 Dieckmann R, Helmuth R, Erhard M, Malorny B: Rapid classification and identification of salmonellae at the species and subspecies levels by whole-cell matrix-assisted laser desorption ionization-time of flight mass spectrometry. Appl Environ Microbiol 2008; 74:7767-7778.

17 Japanese Standards Association: Japanese Industrial Standard (JIS L 1902:2002) testing for antibacterial activity and efficacy on textile products. Japanese Standards Association, 2012.

18 Bastos MC, Mondino PJ, Azevedo ML, Santos KR, Giambiagi-deMarval M: Molecular characterization and transfer among Staphylococcus strains of a plasmid conferring high-level resistance to mupirocin. Eur J Clin Microbiol Infect Dis 1999;18:393-398.
9 Miller MA, Dascal A, Portnoy J, Mendelson J: Development of mupirocin resistance among methicillin-resistant Staphylococcus aureus after widespread use of nasal mupirocin ointment. Infect Control Hosp Epidemiol 1996;17:811-813.

20 Patel JB, Gorwitz RJ, Jernigan JA: Mupirocin resistance. Clin Infect Dis 2009;49:935-941.

21 Thomas CM, Hothersall J, Willis CL, Sompson TJ: Resistance to and synthesis of the antibiotic mupirocin. Nat Rev 2010;8:281-289.

22 Ip M, Lui SL, Poon VK, Lung I, Burd A: Antimicrobial activities of silver dressings: an in vitro comparison. J Med Microbiol 2006; 55:59-63.

23 Percival SL, Bowler PG, Russell D: Bacterial resistance to silver in wound care. J Hosp Infect 2005;60:1-7.

24 Loh JV, Percival SL, Woods EJ, Williams NJ, Cochrane CA: Silver resistance in MRSA isolated from wounds and nasal sources in humans and animals. Int Wound J 2009;6:3238.

25 Hübner N-O, Sieber J, Kramer A: Octenidine dihydrochloride, a modern antiseptic for skin, mucous membranes and wounds. Skin Pharmacol Physiol 2010;23:244-258.

26 McDonnell G, Russell AD: Antiseptics and disinfectants: activity, action and resistance. Clin Microbiol Rev 1999;12:147-179.

27 Mohammadi Z, Abbott PV: The properties and applications of chlorhexidine in endodontics. Int Endod J 2009;42:288-302.

28 Batra R, Cooper BS, Whiteley C, Patel AK, Wyncoll D, Edgeworth JD: Efficacy and limitation of chlorhexidine-based decolonization strategy in preventing transmission of methicillin-resistant Staphylococcus aureus in an intensive care unit. Clin Infect Dis 2010;50:210-217.

29 Thomas L, Russell AD, Maillard J-Y: Antimicrobial activity of chlorhexidine diactetate and benzalkonium chloride against Pseudomonas aeruginosa and its response to biocide residues. J Appl Microbiol 2005;98:533-543.

30 Akinkunmi EO, Lamikanra A: Susceptibility of community asssociated methicillin resistant Staphylococcus aureus isolated from faeces to antiseptics. J Infect Dev Ctries 2012; 6:317-324.

-31 Ho J, Branley J: Prevalance of antiseptic resistance genes $q a c A / B$ and specific sequence types of methicillin-resistant Staphylcoccus aureus in the era of hand hygiene. J Antimicrob Chemother 2012;67:1549-1550.
32 Kunisada T, Yamada K, Oda S, Hara O: Investigation on the efficacy of povidone-iodine against antiseptic-resistant species. Dermatol 1997;195(suppl 2):14-18.

33 Nicoletti G, Boghossian V, Gurevitch F, Borland R, Morgenroth P: The antimicrobial activity in vitro of chlorhexidine, a mixture of isothiazolinones ('Kathon' CG) and cetyl trimethyl ammonium bromide (CTAB). J Hosp Infect 1993;23:87-111.

34 Karen A, Fitzgerald A, Davies A, Russell AD: Sensitivity and resistance of Escherichia coli and Staphylococcus aureus to chlorhexidine. Lett Appl Microbiol 1992;14:33-36.

35 Seipp HM, Körber A: Biofilm, fibrin, resistance - antibacterial measures with focus on polihexanide. European Wound Management Association (EWMA), Helsinki, May 2009.

36 Al-Doori Z, Goroncy-Bermes P, Gemmel CG, Morrison D: Low-level exposure of MRSA to octenidine dihydrochloride does not select for resistance. J Antimicrob Chemother 2007;59:1280-1282.

37 Reimer K, Wichelhaus TA, Schäfer V, Rudolph P, Kramer A, Wutzler P, Ganzer D, Fleischer W: Antimicrobial effectiveness of povidine-iodine and consequences for new applications. Dermatology 2002;204(suppl 1):114-120

38 Oduwole KO, Glynn AA, Molony DC, Murray D, Row S, Holland LM, McCormack DJ, O'Gara JP: Anti-biofilm activity of sub-inhibitory povidone-iodine concentrations against Staphylococcus epidermidis and Staphylococcus aureus. J Orthop Res 2010;28: 1252-1256.

39 Daeschlein G, Assadian O, Bruck JC, Meinl C, Kramer A, Koch S: Feasibility and clinical applicability of polihexanide for treatment of second-degree burn wounds. Skin Pharmacol Physiol 2007;20:292-296.

40 Hirsch T, Jacobsen F, Rittig A, Goertz O, Niederbichler A, Steinau HG, Seipp HM, Steintraesser L: Vergleichende in-vitro-Studie zur Zytotoxizität klinisch eingesetzter Antiseptika. Hautarzt 2009;60:984-991. 